\title{
From Narrow to Open: Improving Learning Readiness through Learning Orientation
}

\author{
Roland K. Yeo, Saudi Arabian Oil Company, Saudi Arabia and \\ University of South Australia, Australia \\ Jessica Li, University of Illinois, Urbana Champaign, USA
}

\begin{abstract}
The paper aims to discuss the potential of improving individual readiness for informal learning through the understanding of learning orientation. Learning orientation is how individuals engage in learning as determined by their self-concept, experience, learning readiness, learning sense, and learning motivation. A person's learning orientation is influenced by contextual factors affecting individual learning capacity. In turn, learning orientation is facilitated by problem solving, sensemaking, and mental framing, particularly when individuals are confronted by challenges outside their work routine. Problem solving can facilitate individuals' sensemaking of circumstances by enhancing their mental framing, which may support or hinder their subsequent problem solving experience. Problem solving is a cognitive process that influences the way individuals interpret a situation for further action. Sensemaking is a spontaneous interpretive process while mental framing is more of a decision making process generating potential scenarios and actions. The paper offers implications for Human Resource Development (HRD) research and practice.
\end{abstract}

Key words: Learning, context, learning orientation, problem solving, sensemaking, mental framing

\section{Introduction}

The disparate streams of Human Resource Development (HRD) research on individual, team, and organizational learning need to be reexamined to further explore how learning and context are intimately related. Learning that occurs in a formal classroom or training context is different to that learning that unfolds real-time in problem solving or work-related contexts. While formal learning suggests a more structured way of knowledge dissemination and exchange in a classroom setting, informal learning often emerges in more spontaneous and generative ways through a variety of dynamics (Choi \& Jacobs, 2011).

In this paper, we discuss the importance of learning and context from the informal learning perspective. Using a practical example of increasing work efficiency in an organization, we suggest that the improvement employees make of their own work could impact others' workflows and outputs related to a larger work system. Therefore, when change occurs, individuals not only need to learn their own work sequence but also how their work might interact with others' work. Therefore, employees need to work together to enhance the efficiency of the final work output as a team. During this process, they ask each other questions, discuss complementariness and discrepancies, solve problems, and modify their action steps. It is during this dynamic process that learning is socially constructed in the context of the organization. For the purpose of this paper, we situate learning in the process of problem solving where learning occurs in the generative and interpretive process of sensemaking, knowledge creation, and action taking that 
will shape organizational practice (Argyris \& Schön, 1996; Guiette \& Vandenbempt, 2016). Learning is at the core of HRD practice and research. This paper seeks to explore how attention to learning orientation can offer HRD practitioners pathways to enhanced practice.

\section{Learning and learning orientation}

Our premise of learning stems from a practice-based perspective where we examine learning as a complex process of socialization evident in everyday work. We suggest that learning is not a natural inclination for individuals in organizations but rather a byproduct of problem solving, sensemaking, and mental framing. Individuals learn when engaging with others in problem solving as they experience overcoming foreseeable traps and developing alternative action steps to improve performance (Jordan \& Audia, 2012).

Learning is socially constructed where interaction dynamics could affect learning orientation which, in turn, facilitates further learning in individuals. Learning orientation is the individual characteristic toward learning and determines a learner's cognitive and behavioural response to the conditions of learning. It also promotes the facilitation of generative conversations, feedback loops, self-reflection, and the understanding of certain issues (Choi \& Jacobs, 2011). Consequently, learning orientation might motivate learners to go beyond their current understanding by questioning underlying assumptions and seeking new knowledge through inquiry and dialogue (Tran et al., 2016). Often, learning orientation begins with the self, motivating individuals to draw on their self-awareness, past experience, and readiness before they engage in learning (Marquardt \& Yeo, 2012). Therefore, it is our belief that by offering an integrated perspective of learning orientation, this paper explores learning as it occurs in problem solving contexts with learning orientation as a way of helping to increase the learning readiness and learning capacity of individuals.

\section{Theoretical Assumptions}

We differentiate learning as a process from learning as an outcome. This means individuals learn at various points and consolidate their learning to make better sense of a particular context (Weick, 1996). The transitory nature of learning as a process allows individuals to develop appropriate actions to respond to contextual stimuli such as routine or urgent issues. In this respect, learning in context constantly enables individuals to modify their thinking and behavioural patterns as a response to the dynamics of that context; a process similar to osmosis - changing its patterns based on how work unfolds (Mintzberg et al., 2005). Therefore, learning is a process that facilitates modifications in the cognitive and behavioural response to emerging complexity (Bennis, 1969). In other words, when faced with non-routine circumstances, individuals could learn spontaneously as different contextual stimuli increase their interpretation and level of consciousness about the surrounding phenomena (Maitlis \& Christianson, 2014). Heightened sensemaking, as individuals socialize with others, will enable them to confront emerging issues and seek ways of improving their way of work while experiencing the continuity and discontinuity of routines (Levitt \& March, 1988).

Individuals in the workplace are frequently curious about the causes of disruptive routines, including unexpected changes and urgent requests as these may throw them out of their comfort zone and shift their focus to the less familiar tasks. In doing so, they may engage in conversations 
with their colleagues to make sense of what is going on and develop interpretive approaches through sensemaking and mental framing to enhance their understanding of a particular context (Weick \& Westley, 1996). Such approaches involve deeper learning through feedback loops and propositions to mitigating those disruptions caused by emerging issues or challenges. In other words, they develop their theories-in-use by formulating potential action steps that reinforce their perception of the social world as a response to a complex or unexpected situation (Argyris \& Schön, 1996). For instance, when an employee, John, has been asked to deliver a presentation to senior management the following day about a business-related concern, he is likely to develop immediate learning strategies to fulfil an unexpected and urgent task. John needs to first make sense of the problem (urgent presentation) and the context (in front of senior management), and dissect the challenge into smaller units through feedback and dialogue perhaps with his supervisor and colleagues in order to garner their support. Following that, he needs to develop appropriate frames of references to make sense of the required data in order to identify plausible action steps (theories-in-use) to satisfy the requirements of the task. Simply put, John's learning orientation may increase his curiosity to learn more about that business concern through problem solving, sensemaking, and mental framing. In what follows, we discuss how learning is intimately bound in context and its relationship with learning orientation.

\section{Learning about learning and context}

Organizations function in many respects like organisms as "individuals develop the personalities, personal habits, and beliefs over time, organizations develop world views and ideologies" (Hedberg, 1981, p. 6). In other words, the cognition (thinking) and behaviour (action) of individuals could influence one another to think and act differently to accomplish a shared task. The collective interactions and their dynamics over time are recorded in organizational memories that "preserve certain behaviours, mental maps, norms, and values" (Bennis, 1969, p. 6). Therefore, human relationships form the basis for collective thinking and action, including the way individuals learn. Organizations also have the capacity to promote learning through dialogue, feedback, and reflection that inform particular actions by creating the conditions for individuals to learn with and from one another, a process similar to osmosis (Jordan \& Audia, 2012).

The collective cognition of individuals could recreate multiple mental frames that facilitate a deeper sensemaking of a particular context. That said, not every individual will learn at the same rate and depth, the capacity of which depends largely on the nature of their work and the extent to which learning outcomes can be expected (Edmondson, 1999). Consequently, the readiness to learn becomes a point of contention when individuals are placed in a context of teams working on projects or solving a pressing work problem. At times, individuals' readiness to learn is hampered by defensive routines in such a way that the longer they are on the job the more resistant they are in embracing change. Learning could therefore be of a high or low level depending on a variety of factors, including individual readiness, nature of task, environmental complexity, and the motivation to learn.

Our theoretical assumptions continue to reinforce the dialectical relationship between learning and context. The extent to which individuals learn is not only dependent on their readiness but also other contextual triggers such as relationship and task structures. After all, learning often orientates toward creating "a sense of order and make arrangements with each other, both to achieve security and to meet material needs" (Watson, 1995, p. 222). Although it is assumed that context changes with time, it can be stabilized when individuals frame it in such a way that 
makes sense to them (Johns, 2001). In particular, context could be stabilized when identifiable action patterns are able to make a difference to the tasks at hand (Brown \& Duguid, 1991). Mowday and Sutton (1993, p. 198) defined context as "stimuli and experience that surround and thus exist in the environment external to the individual", suggesting that the response to a context can be controlled by how one makes sense of the context one is in.

From the perspective of learning, context provides the basis, either as constraints or opportunities, for the modification of behaviours and attitudes in a particular setting (Johns, 2001). Context facilitates the learning of individuals as it offers the description and portrayal of a particular phenomenon (Maitlis \& Christianson, 2014). Despite being external to the individual, context does not present itself as a separate existence in the messiness of the objective world. Instead, it is shaped and reified by the language projected by individuals through ongoing problem solving and sensemaking (Weick, 1996). To a large extent, context can influence both the thinking and action of individuals, influencing the degree and rate at which they learn (Levitt \& March, 1988).

\section{(Re)Thinking learning orientation}

Taking our understanding of learning and context further, learning orientation could be perceived as a personal trait, a desire for continuous learning despite any challenges and setbacks. When an individual is always open to new opportunities for self-improvement by acquiring new knowledge and skills to enhance his or her competencies, we define this individual as having an open learning orientation (Tran et al., 2016). On the contrary, when an individual resists change or avoids learning new things, we define this individual as having a narrow learning orientation. An individual with an open learning orientation keeps an open mind and adopts a proactive mindset by turning problems into opportunities for learning. Learning-oriented behaviours include commitment to learning, open-mindedness, trust, and collaboration (Raemdonck et al., 2014). If we put learning orientation on a continuum from narrow to open (see Figure 1), we could realize that when individuals possess a learning orientation toward the open end of the continuum, they are more likely to engage in dynamic feedback, risk taking, and improvised action steps, thereby increasing their capacity to learn. They are also more willing to share knowledge with others without a competitive tendency. On the contrary, when individuals' learning orientation moves toward the narrow end of the continuum, they are more likely to engage in actions that resist change, risk taking, and improvising, thereby decreasing their capacity to engage in new learning (Lee et al., 2015).

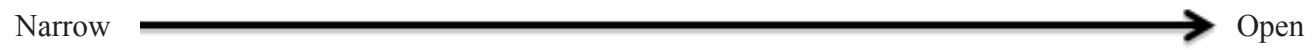

Self-concept; Experience; Learning readiness; Learning sense; Learning motivation

Figure 1: Learning orientation continuum

According to Marquardt and Yeo (2012), learning orientation is influenced by the following five factors: self-concept, experience, readiness to learn, orientation to learn, and motivation to learn. Self-concept is the ability of individuals to command their own mental framing when engaging in their work and the ability to shift their mental framing by drawing on specific cues from their immediate context. When moving toward a more open learning orientation, they will have control of their own mental framing to absorb the contextual cues. Experience is cumulated critical resources that give individuals confidence in learning, particularly in the context of problem solving. Learning readiness is individuals' awareness of their tasks at hand and the social roles 
they assume in performing those tasks through individual and collective sensemaking. Learning sense prompts individuals to develop a sense of urgency that guides their knowledge utilization and action, particularly in times of challenges. Finally, learning motivation helps individuals to identify the purpose and value of learning to achieve personal success, affecting their capacity to frame and make sense of emerging issues.

The combination of the five factors will influence a persona's placement on the learning orientation continuum. As learners become more aware of themselves and their surroundings, have more problem solving experiences, and increase in learning readiness, learning sensibility, and learning motivation, they will move toward the open end of the continuum. They will be more accepting of learning experiences, ready to learn, less afraid to express their own ideas, and more motivated to learn continuously.

\section{Significance of Learning, Context, and Learning Orientation}

Organizations aim to learn faster than others in order to remain competitive in current volatile times. Individuals are expected to learn on their jobs and develop learning strategies to help them respond to emerging changes (Raemdonck et al., 2014). One of the critical strategies is the ability to develop feedback loops that challenge and support the existing understanding of a particular context. Feedback as a tool to jolt people's thinking could amplify or restrict learning, depending on their learning orientation and the context at work. For instance, if individuals are not ready to learn (toward a narrowly defined learning orientation on the continuum) or experience a lack of trust in the people they are working with (the context), they are less likely to participate in feedback interactions that will promote the processes of sensemaking, mental framing, and problem solving. On the other hand, if they are motivated and open to solving a collective work-related problem and the trust is high, they are more likely to engage in learning. They will learn by challenging each other's ideas and suggestions through constructive feedback (Argyris \& Schön, 1996) that promotes the processes of mental framing, sensemaking, and problem solving. When challenged with ambivalent roles in a changing situation, individuals will potentially draw on their self-concept, past experience, learning readiness, learning sense, and learning motivation to develop coping strategies in order to make sense and resolve the tasks at hand (Hahn et al., 2014). This example demonstrates how learning orientation works to influence mental framing, sensemaking, and problem solving.

In studying learning in organizations, Senge (1990) suggested that mental models in the way individuals view their environment help them to be more aware of the variables that constitute their work. The perception and understanding of their context create opportunities to see connections between what they need to accomplish and the impact of their work on the organization. Collectively, individuals influence one another by allowing their mental models to interact through dialogue, feedback, and reflection through knowledge sharing (Lee et al., 2015). The higher the level of interaction the greater the level of sensemaking as individuals share their mental models to help each other better understand their context (Weick, 1996). Dynamic sensemaking could lead to plausible actions in problem solving that are developed according to their theories-in-use (Argyris \& Schön, 1996).

Theories-in-use could help explain how individuals develop and refine their mental maps to influence their decision making. However, when interactional dynamics become more complex, 
individuals may not be able to relate their mental models to their envisaged actions. They may overlook the unintended consequences of certain actions that could provide opportunities for learning. As such, in situations where power and politics undermine human relationships, individuals may become wary of their environment preventing them from learning from one another through mutual questioning and dialogue (Argote \& Spektor-Miron, 2011). However, individuals can potentially work around any prevailing politics to seek opportunities for informal learning such as the sharing of experience, mentoring, and job assignments (Choi \& Jacobs, 2011). If individuals are more sensitive to their changing contexts, they are likely to be more open to sharing their mental models with others to create the conditions for ongoing sensemaking, reflection, and action taking (Maitlis \& Christianson, 2014). Individuals could also build networks to expand their learning and redefine the context to promote collaborative learning (Brown \& Duguid, 1991). When learning orientation moves toward the open end of the continuum, individuals enjoy a mutually supportive environment where they communicate and participate in dialogue of their interpretive experience to expand their learning (Tran et al., 2016).

\section{Problem Solving, Sensemaking, and Mental Framing}

Consider a real case scenario in a multinational company where learning is challenged in a complex context, as presented in Figure 2. It will be used as a basis for discussion to shed light on the occurrence of learning orientation through problem solving, sensemaking, and mental framing.

A symposium Team $\mathrm{X}$ was working on was not making any desirable progress due to a case of 'too many cooks spoiling the broth', leading to a misalignment of expectations from different stakeholders, including internal customers and external vendors. Time was running out. Two of their keynote speakers and one of the major sponsors pulled out of the programme. Given the short notice, the programme could not be publicized on time to generate an optimal response from their industry partners. More critically, the team was confronted by conflicting decisions from two supervisors at a time when the main supervisor, Dave, had just returned from his annual vacation. During his absence, an acting supervisor, Mark, from another department was appointed to cover Dave's responsibilities temporarily. It was during the time of transition between the incoming and outgoing supervisors that some political tension was experienced by Team X. Mark took a bold approach to modifying some of the major decisions regarding the symposium that Dave had made earlier. For instance, Mark insisted that the programme be completely revised and the duration of the event be extended to a full day instead of half a day. He also reduced the presentation duration of the keynote speakers from an hour to 30 minutes, the rationale of which was to include more speakers in the programme. Little did Mark realize that his decision had caused undue misunderstanding with the keynote speakers who, in retaliation, decided to turn down the invitation at the very last minute. The sponsor that pulled out was also confused as to the scope and intent of the event. Dave was shocked to learn of the mess created by Mark and decided to take back his control. The clash of opinions indeed led to political rifts on many fronts. Not only did Team X have to deal with internal politics but they also had to come up with urgent, alternative solutions before meeting with their Senior Vice President (SVP) for an update. The SVP would like to be updated of the symposium preparation on a regular basis. Team X had to come up with ideas that would appease different parties, not least Dave and Mark.

Figure 2: Case Scenario 
First, problem solving is not only a skill but also a cognitive process that draws upon individuals' interpretive capacity for complex issues, including developing and modifying specific mental frames, to identify plausible solutions (Hahn et al., 2014). When individuals are confounded by pressing issues, they search for meanings around the phenomena figuring out the causes and potential complications. Second, they make connections using implicit and explicit contextual signals such as people, political climate, and company expectations, a process similar to "temporal interconnectivity" in sensemaking (Guiette \& Vandenbempt, 2016, p. 86). Third, individuals engage in mental framing as they interpret and connect with these signals by creating a mental template and label it with information (Marquardt \& Yeo, 2012).

Conflicting signals arising from political tension could lead to temporal, disruptive learning where learners try to fall back on their past experience to guide their next steps. However, as past experiences collide between individuals, they start developing plausible scenarios of how power and politics might be used to achieve certain outcomes. Unravelling political undertones could help increase their learning orientation to ask more questions and discuss possible solutions. Therefore, we suggest that problem solving can facilitate or develop individuals' sensemaking capacity by reinforcing or challenging their mental framing, which will in turn enable or constrain their subsequent problem solving experience.

Next, we discuss the connection between learning orientation and the tri-factors (problem solving, mental framing and sensemaking), and how they may work to increase individual learning readiness and learning capacity using the above Figure 2.

\section{Learning orientation and problem solving}

Team X was confronted by an urgent need to reconstruct their story for the Senior Vice President (SVP) but they also realized the increasing tensions caused by both internal and external factors and, not surprisingly, not all factors were within their control. Such tensions can function as a catalyst to generate learning which allowed Team $\mathrm{X}$ to shift their perspective of the current situation to a much larger vision without losing sight of the pressing issue at hand. Still, the team had to face the pressure of pleasing their supervisors and updating the SVP about their re-strategized plans. In this case, the team orientated toward problem solving by combining their past experiences and heightened learning sense to re-conceptualize the symposium. As they moved along the continuum from narrow to open through questioning and reflection, they became increasingly desensitized to the underlying issues. This allowed them to detach themselves from the familiarized assumptions of the problem and view the overall context much more clearly.

Engaging others outside their sphere of familiarity such as consultants, contractors, and vendors, also helped them consider other facets of the problem, opening them up to alternative perspectives they had not considered earlier (Engeström, 2001). Through input from a variety of stakeholders, Team X was able to drastically alter the programme by modifying the theme to allow wider participation from various industries. This opened up much wider contacts through personal networking which helped secure new speakers, sponsors, and exhibitors within a short time. Getting both internal and external inputs led to validation of their symposium ideas, appeasing the political conflict between the two supervisors. Being more open on the learning orientation continuum suggests thinking outside the comfort zone which offers deeper learning on the reflective level. Team $\mathrm{X}$ was able to turn their problem solving into a creative pursuit by simply increasing their learning orientation. 
What might be regarded as errors such as the lack of a backup plan for non-confirming speakers or sponsors could potentially be viewed as an opportunity for experimenting with alternative solutions (Marquardt \& Yeo, 2012). Engaging in the sensemaking of the plausible causes of the problem released an overt motivation for Team $\mathrm{X}$ to re-conceptualize their understanding of "symposium". Thinking beyond their comfort zone opened up opportunities for deeper reflective learning, where they viewed their existing limitations in how a symposium could be presented as a potential trigger for greater innovation (De Stobbeleir et al., 2011).

\section{Learning orientation and sensemaking}

Sensemaking is a cognitive process that helps individuals to organize meanings around known and unknown variables, particularly when non-routine or unexpected challenges could disrupt or even distort the way we view our work (Weick, 1996). When Team X was facing time constraints, they drew on the political signals from their supervisors and their interpretation of senior management's expectations to make sense of the urgency of the problem. For instance, the calibre of speakers expected by their senior management should be of high profile and varied. Articulating the questions they had in their minds amplified their framing of the context as contextual cues. Cues such as SVP meeting and publicity lag time served as stimuli helping them make connections to the problem issues (Maitlis \& Christianson, 2014). As they began communicating their perception of the situation, including their feelings and potential consequences, they engaged in a variety of sensemaking mechanisms through interactive feedback to help each other connect with the contextual cues (Hahn et al., 2014). Team X engaged in a more reflective level of learning as the envisaged problem seemed to intensify. They began to fall back on their past experiences to help them construct a vision of their future using the present as a reference of how the vision could be reconstructed (Weick \& Westley, 1996). For instance, they considered the involvement of Government agencies and Gen Y professionals to add a different flavour to the symposium. They also considered tradeoffs and internal conflicts, such as the possibility of not including any of the speakers expected by the SVP, not least the pressure of presenting the symposium to the political satisfaction of the senior management. Deeper sensemaking of the conflicting issues helped them get around the entrapment of what their management had expected versus what the audience might benefit from the symposium.

Internalizing the different aspects of the problem helped Team X develop different mental representations of how the symposium might ultimately look like. In the process, sensemaking of their role, the political conflict between their supervisors, the SVP's reaction, and the ultimate event itself led them to viewing the problem as a timely opportunity for proving their own fears completely unfounded. Once they became less fixated with their preconceived understanding of the problem, they began modifying their mental pictures of how the symposium might be organized differently given the severe time constraints. They even thought of transferring the organizing of the event to the Public Relations Department that had far much greater resources. The collective sensemaking process ultimately increased Team X's learning readiness and learning sense as they moved along the learning orientation continuum toward open learning experiences.

\section{Learning orientation and mental framing}

While sensemaking is a spontaneous cognitive process drawing on contextual cues to shape individuals' perception of reality (Weick, 1996), mental framing is more of a decision making 
process that helps the problem solver focus on specific boundaries of an issue leading to the formulation of specific actions (Guiette \& Vandenbempt, 2016). Mental framing operates by means of consolidating the sensemaking material and categorizing it into meaningful units that inform the problem solver of the next steps. The mental framing process of Team X was initially quite narrow as there was concern that the symposium might turn out be a negative example in the company's history. However, it took a turn for a more positive representation of a symposium that could be quite innovative in nature.

In mental framing, the push and pull factors can create a learning rupture. This is where Team $\mathrm{X}$ simply allowed multiple cognitive frames to serve as alternative paths for addressing the same problem (Hahn et al., 2014). The rupture can take the form of radical thinking and courageous experimentation that redefines the problem context. Team $\mathrm{X}$ adopted more of a divide-andconquer approach where each negative mental frame would be counteracted by a positive one. For instance, what was envisaged as a disastrous event could be elevated to a corporate level by involving their personal networks and company experts such as Public Relations to redefine and co-organize the symposium. In essence, Team X unlearned their fear of facing the consequences and relearned the opportunity presented to them by turning things around despite the odds. In other words, they experienced a rupture between unlearning and relearning, increasing their interpretive capacity to frame the challenges in more specific ways (Hedberg, 1981).

Mental framing could influence decision making where different mental pictures can provide specific scenarios that help individuals determine plausible actions. It involves the rethinking and reassessment of various mental representations that help individuals make sense of their intended actions (Weick \& Westley, 1996). For instance, a Team X member suggested paying for a celebrity speaker to increase the visibility of the symposium when financial constraints were in fact a major concern. The courage to frame the situation radically provides the sensemaking material for further reframing. Quite ironically, the celebrity suggestion sparked off new mental frames around getting potential sponsors to pay for speakers, involving Government agencies and major industries as part of their corporate citizenship programmes, and deploying the Gen Y population to inject forward-thinking ideas. Dynamic mental framing ultimately led Team X to increasing their learning orientation through internal dialogue and external feedback.

We further demonstrate how mental framing can reinforce the characteristics of learning orientation to play out in the dilemmas of Team X (see Figure 2). First, Team X applied their self-concept by making sense of the challenges confronting the symposium and recognizing their ability to change things around. Second, they generated tacit knowledge by sharing each other's past experience through critical lessons learned to help them develop the next plausible steps. Third, they went out of their comfort zone to consider the worst case scenario by exploring radical approaches to organizing the symposium despite their fear of the SVP rejecting their ideas. This increased their learning readiness to change the game plan. Fourth, they took proactive steps to listening and internalizing feedback from each other by developing a greater learning sense of where they were heading in terms of programme redesign. Fifth, once the team realized the value of going through times of urgency and complexity, their learning motivation increased as they were more open to asking tough questions and accepting each other's feedback. These learning behaviours ultimately interacted to develop a more open learning orientation on the continuum (Figure 1). 


\section{Implications for HRD Research and Practice}

Human Resource Development prides itself as the promoter and provider of employee learning and development to unleash human potential. HRD practitioners often focus on the activities of design and development of new training programmes and activities, and in this article we call attention to the concept of learning orientation. We believe promoting the openness of employees' learning orientation can encourage positive attitudes toward learning when faced with challenging real-life situations. Through integrating the processes of problem solving, sensemaking, and mental framing, individuals and teams could formulate learning orientations that increase their learning capacity.

First of all, we encourage HRD practitioners to recognize the importance of learning orientation in employee learning and development. Learning orientation determines individuals' attitude toward learning, especially when faced with challenging situations. Employees with a learning orientation toward the open end of the continuum are more likely to view challenges as learning opportunities. It can increase their capability to overcome obstacles in work situations through increased self-concept, heightened learning readiness, learning sense, and learning motivation. It can sharpen their mental framing to solve any problems at hand. Developing learning interventions to promote openness in an employee's learning orientation can lead to enhanced practice impact.

Second, researches have shown that employees learn most of their work-related knowledge from informal learning (Eraut, 2004). Learning orientation has been shown to influence informal learning (Choi \& Jacobs, 2011). Informal learning is a spontaneous, generative, and self-directed learning activity. It often occurs while employees are in the process of solving work problems. In this process, employees learn by generating and creating new knowledge and take actions to reshape organization practices (Argyris \& Schön, 1996). Hence, it is important to nurture individual learning orientation toward the open end of the continuum by creating an environment that supports trust, questioning, and dialogue (Argote \& Spektor-Miron, 2011). Organizations that support open exchange with a safe and trusting environment for employees to conduct their own sensemaking and mental framing will likely produce new knowledge and new procedures at a faster pace.

An organizational learning environment plays an important role in employee learning in both formal and informal settings (Choi \& Jacobs, 2011). When an organization rewards learning, it will promote a learning culture that reinforces an open learning orientation. Hence, employees will be empowered to engage in the learning process through problem solving, sensemaking, and mental framing. Problem-based learning is collaborative and collective in nature which involves a team of individuals working together. To promote a corporate culture that endorses self-concept, encourages experimentation, learning readiness, learning sense, and learning motivation, learning orientation should be on the agenda of HRD practitioners.

The dynamics of an employee's problem solving, sensemaking, and mental framing experience could be enabled or constrained by his or her learning orientation. We illustrate the five characteristics of learning orientation, their related learning behaviours, and suggested actions for HRD practitioners in Table 1. Learning orientation is a practical process which can be facilitated through appropriate interventions in relation to the desired learning behaviours for particular situations. The levels at which potential learning interventions are designed largely 
depend on individual and group readiness as well as organizational culture. Individual learning preferences, collaborative opportunities, and available resources also play a critical role in facilitating learning orientation.

\begin{tabular}{|c|c|c|c|}
\hline Factors & $\begin{array}{l}\text { Learning } \\
\text { Behaviours }\end{array}$ & $\begin{array}{l}\text { Guiding Questions for HRD } \\
\text { Practitioners }\end{array}$ & Suggested Actions \\
\hline $\begin{array}{l}\text { Self- } \\
\text { concept }\end{array}$ & $\begin{array}{l}\text { Learners reflect } \\
\text { on their personal } \\
\text { strengths and } \\
\text { weaknesses } \\
\text { by exploring } \\
\text { opportunities to } \\
\text { improve themselves. } \\
\text { They learn to apply } \\
\text { their knowledge } \\
\text { and skills in areas } \\
\text { where they are most } \\
\text { confident in and may } \\
\text { take on challenges } \\
\text { that will stretch } \\
\text { their competencies } \\
\text { further. }\end{array}$ & $\begin{array}{l}\text { How can we increase the self- } \\
\text { introspection of employees } \\
\text { through self-assessment } \\
\text { tools? } \\
\text { How can we help employees } \\
\text { identify their strengths and } \\
\text { weaknesses to enhance their } \\
\text { individual performance? } \\
\text { What kind of HRD } \\
\text { programmes or interventions } \\
\text { can help employees align } \\
\text { their personal interests } \\
\text { and goals to those of the } \\
\text { organization? }\end{array}$ & $\begin{array}{l}\text { Deploy a variety of psychometric } \\
\text { surveys or instruments to help } \\
\text { employees learn more about } \\
\text { their personality, emotional } \\
\text { intelligence, etc. } \\
\text { Design a dynamic feedback system } \\
\text { that will encourage supervisors to } \\
\text { engage in ongoing constructive } \\
\text { conversations with their employees } \\
\text { about their performance. } \\
\text { Incorporate goal development in } \\
\text { the performance appraisal system } \\
\text { where the required competencies } \\
\text { relating to the organization's } \\
\text { strategic objectives are specified } \\
\text { and communicated. }\end{array}$ \\
\hline Experience & $\begin{array}{l}\text { Learners draw on } \\
\text { their past experience } \\
\text { to develop relevant } \\
\text { actions that } \\
\text { will meet their } \\
\text { current needs and } \\
\text { challenges. } \\
\text { They learn to } \\
\text { modify their } \\
\text { assumptions about } \\
\text { their social world } \\
\text { and participate in } \\
\text { the very dynamics } \\
\text { that characterize } \\
\text { their identity and } \\
\text { work. }\end{array}$ & $\begin{array}{l}\text { How can we help employees } \\
\text { to reflect on their concrete } \\
\text { experience and share their } \\
\text { lessons learned with others? } \\
\text { How can we create the } \\
\text { context for employees to } \\
\text { experience their learning in } \\
\text { meaningful ways? } \\
\text { What kind of HRD } \\
\text { programmes or interventions } \\
\text { can help employees capture } \\
\text { their learning experience } \\
\text { and use it as a source } \\
\text { of enhancing learning } \\
\text { performance? }\end{array}$ & $\begin{array}{l}\text { Encourage employees to develop } \\
\text { a learning log with guided } \\
\text { questions to help them frame } \\
\text { their experience and identify } \\
\text { specific lessons learned from their } \\
\text { individual performance. } \\
\text { Develop a culture of group } \\
\text { knowledge sharing using } \\
\text { work-based issues as triggers } \\
\text { for the exchange of individual } \\
\text { experiences. } \\
\text { Encourage employees to develop } \\
\text { work-based applications that } \\
\text { address specific business- } \\
\text { related issues and document } \\
\text { their experience based on each } \\
\text { application or experimentation. }\end{array}$ \\
\hline
\end{tabular}




\begin{tabular}{|c|c|c|c|}
\hline $\begin{array}{l}\text { Learning } \\
\text { Readiness }\end{array}$ & $\begin{array}{l}\text { Learners perceive } \\
\text { their immediate } \\
\text { context as a } \\
\text { platform for } \\
\text { learning and engage } \\
\text { in activities that } \\
\text { challenge their } \\
\text { current thinking. } \\
\text { They learn to } \\
\text { approach challenges } \\
\text { as opportunities for } \\
\text { learning by getting } \\
\text { out of their comfort } \\
\text { zone to acquire } \\
\text { new knowledge and } \\
\text { skills. }\end{array}$ & $\begin{array}{l}\text { How can we help employees } \\
\text { to learn continuously through } \\
\text { formal and informal ways? } \\
\text { How can we prepare } \\
\text { employees to challenge } \\
\text { themselves by exploring } \\
\text { alternative perspectives of } \\
\text { common issues? } \\
\text { What kind of HRD } \\
\text { programmes or interventions } \\
\text { can help employees to } \\
\text { ask good questions when } \\
\text { confronted by work } \\
\text { challenges? }\end{array}$ & $\begin{array}{l}\text { Involve employees in cross- } \\
\text { functional projects or initiatives } \\
\text { to break their routine of familiar } \\
\text { work and hold them accountable } \\
\text { for learning and outcome. } \\
\text { Involve employees in regular } \\
\text { performance reviews of specific } \\
\text { business functions to help } \\
\text { them learn from the business } \\
\text { performance and identify ways } \\
\text { for improvement. } \\
\text { Encourage an open learning } \\
\text { culture where employees are free } \\
\text { to raise any questions or concerns } \\
\text { to determine root causes of issues } \\
\text { without being blamed. }\end{array}$ \\
\hline $\begin{array}{l}\text { Learning } \\
\text { Sense }\end{array}$ & $\begin{array}{l}\text { Learners develop } \\
\text { a response } \\
\text { mechanism to help } \\
\text { them identify their } \\
\text { learning needs in } \\
\text { order to improve } \\
\text { themselves. } \\
\text { They learn to } \\
\text { take proactive } \\
\text { steps to seek and } \\
\text { internalize feedback } \\
\text { to determine the } \\
\text { most appropriate } \\
\text { approach to learning } \\
\text { from others. }\end{array}$ & $\begin{array}{l}\text { How can we help employees } \\
\text { to determine their knowledge } \\
\text { and skill gaps to enhance } \\
\text { their job performance? } \\
\text { How can we provide } \\
\text { employees different learning } \\
\text { options to help them acquire } \\
\text { the necessary knowledge and } \\
\text { skills efficiently? } \\
\text { What kind of HRD } \\
\text { programmes or interventions } \\
\text { can help employees increase } \\
\text { their learning capacity? }\end{array}$ & $\begin{array}{l}\text { Ensure that employees have } \\
\text { an individual professional } \\
\text { development plan that is aligned } \\
\text { to the competencies required for } \\
\text { their jobs. } \\
\text { Discuss with employees the } \\
\text { different avenues that can support } \\
\text { their learning based on personal } \\
\text { interests and business needs. } \\
\text { Create a safe and blame-free } \\
\text { learning environment that } \\
\text { celebrates employees' mistakes } \\
\text { where the lessons learned } \\
\text { can contribute to continuous } \\
\text { improvement. }\end{array}$ \\
\hline $\begin{array}{l}\text { Learning } \\
\text { Motivation }\end{array}$ & $\begin{array}{l}\text { Learners understand } \\
\text { the value of learning } \\
\text { and actively seek } \\
\text { feedback about } \\
\text { their performance } \\
\text { in order to develop } \\
\text { strategies for } \\
\text { improvement. } \\
\text { They learn to } \\
\text { develop specific } \\
\text { learning goals that } \\
\text { are aligned to their } \\
\text { career interests } \\
\text { and job-related } \\
\text { outcomes. }\end{array}$ & $\begin{array}{l}\text { How can we help employees } \\
\text { to make sense of their } \\
\text { learning at work? } \\
\text { How can we motivate } \\
\text { employees to take their } \\
\text { learning seriously even when } \\
\text { handling routine tasks? } \\
\text { What kind of HRD } \\
\text { programmes or interventions } \\
\text { can help employees } \\
\text { develop learning goals } \\
\text { that are meaningful and } \\
\text { developmental? }\end{array}$ & $\begin{array}{l}\text { Recognize employees' learning } \\
\text { efforts by showing appreciation } \\
\text { and relating them to their } \\
\text { professional development plans. } \\
\text { Engage in regular dialogue and } \\
\text { feedback with employees regarding } \\
\text { their job performance by reinforcing } \\
\text { their strengths and emphasizing } \\
\text { continuous improvement. } \\
\text { Involve employees in the design } \\
\text { of their individual professional } \\
\text { development plans by helping them } \\
\text { develop short, medium, and long- } \\
\text { term learning goals with specific } \\
\text { impact on their job performance. }\end{array}$ \\
\hline
\end{tabular}

Table 1: Characteristics of learning orientation 


\section{Conclusion}

In this paper, we have argued that learning and context are intimately bound, and learning at the individual level could be better understood if we examined learning orientation as enacting through the interplay of problem solving, sensemaking, and mental framing. As individuals engage in their daily activities with an increased awareness of themselves and their immediate context, they can develop a deeper interpretive capacity to make better sense of their work and environment. We have advocated that HRD practice recognizes and addresses employees' learning orientation through various learning and development activities.

The paper recognizes several limitations. First, we realized that learning orientation could be given a more in-depth conceptual exploration at the individual and group level. Taking the cue that "organizing and learning are essentially antithetical processes" (Weick \& Westley, 1996, p. 440), we suggest exploring the tension that is experienced but not conceptually explained between contextual disruption and learning orientation, based on external factors such as changes in economy, industry trends, and market demands. It would also be interesting to explore internal factors such as learner control and learning choice as affecting learning orientation. As Torraco (1999, p. 259) suggested, "development to enhance the skilled performance of employees cannot be separated from the context in which the performance is expected to occur". Future studies could empirically explore the cognitive and behavioural impact of problem solving on learning orientation.

Taking the individual level of learning to another level, future research could consider how member interdependence could lead to different stages of intimacy in group problem solving (c.f. Marquardt \& Yeo, 2012), influencing collective sensemaking and mental framing (c.f. Guiette \& Vandenbempt, 2016). For instance, individual learning orientation could have an influence on group learning capacity (c.f. Tran et al., 2016). Only then can learning orientation be positioned as a multilevel construct offering a more encompassing conceptual perspective of the relationship between learning and context (Choi \& Jacobs, 2011).

\section{References}

Argote L., \& Spektor-Miron, E. (2011). Organizational learning: From experience to knowledge. Organization Science, 22(5), 1123-1137.

Argyris, C., \& Schön, D. (1996). Organizational learning II: Theory, method, and practice. Reading, MA: Addison-Wesley.

Bennis, W. G. (1969). Organization development: Its nature, origins and prospects. Reading, MA: AddisonWesley.

Brown, P. S., \& Duguid, P. (1991). Organizational learning and communities-of-practice: Toward a unified view of working, learning, and innovating. Organization Science, 2(1), 40-58.

Choi, W., \& Jacobs, R. L. (2011). Influences of formal learning, personal learning orientation, and supportive learning environment on informal learning. Human Resource Development Quarterly, 22(3), 239-257.

De Stobbeleir, K. E. M., Ashford, S. J., \& Buyens, D. (2011). Self-regulation of creativity at work: The role of feedback-seeking behavior in creative performance. Academy of Management Journal, 54(4), $811-831$.

Edmondson, A. (1999). Psychological safety and learning behavior in work teams. Administrative Science Quarterly, 44(2), 350-383.

Engeström, Y. (2001). Expansive learning at work: Toward an activity theoretical reconceptualization. Journal of Education and Work, 14(1), 133-156. 
Eraut, M. (2004). Informal learning in the workplace. Studies in Continuous Education, 26(2), 247-273.

Guiette, A., \& Vandenbempt, K. (2016). Learning in times of dynamic complexity through balancing phenomenal qualities of sensemaking. Management Learning, 47(1) 83-99.

Hahn, T., Preuss, L., Pinkse, J., \& Figge, F. (2014). Cognitive frames in corporate sustainability: managerial sensemaking with paradoxical and business case frames. Academy of Management Review, 39(4), 463-487.

Hedberg, B. (1981). How Organizations learn and unlearn. In P. C. Nystrom, and W. H. Starbuck (Eds.), Handbook of organizational design (pp. 3-27). Oxford: Oxford University Press.

Johns, G. (2001). In praise of context. Journal of Organizational Behavior, 22(1), 31-42.

Jordan, A. H., \& Audia, P. G. (2012). Self-enhancement and learning from performance feedback. Academy of Management Review, 37(2), 211-231.

Lee, S., Yoo, Y., \& Yun, S. (2015). Sharing my knowledge? An interactional perspective. Journal of Managerial Psychology, 30(8), 986-1002.

Levitt, B., \& March, J. G. (1988). Organizational learning. Annual Review of Sociology, 14(1), 319-340.

Maitlis, S., \& Christianson, M. (2014). Sensemaking in organizations: Taking stock and moving forward. Academy of Management Annals, 8(1), 57-125.

Marquardt, M., \& Yeo, R. K. (2012). Breakthrough problem solving with action learning: Concepts and cases. Palo Alto, CA: Stanford University Press.

Mintzberg, H., Ahlstrand, B., \& Lampel, J. (2005). Strategy bites back: It is a lot more, and less, than you ever imagined. Englewood Cliffs, NJ: Pearson-Prentice Hall.

Mowday, R. T., \& Sutton, R. I. (1993). Organizational behavior: Linking individuals and groups to organizational contexts. Annual Review of Psychology, 44(1), 195-229.

Raemdonck, I., Gijbels, D., \& van Groen, W. (2014). The influence of job characteristics and self-directed learning orientation on workplace learning. International Journal of Training and Development, 18(3), 188-203.

Senge, P. (1990). The fifth discipline: The art and practice of the learning organization. New York, NY: Doubleday.

Torraco, R. J. (1999). Integrating learning with working: A reconception of the role of workplace learning. Human Resource Development Quarterly, 10(3), 249-270.

Tran, T. B. H., Oh, C. H., \& Choi, S. B. (2016). Effects of learning orientation and global mindset on virtual team members' willingness to cooperate in: The mediating role of self-efficacy. Journal of Management and Organization, 22(3), 311-327.

Watson, T. (1995). Toward a managerially relevant but non-managerialist organization theory. In J. Hassard, \& M. Parker (Eds.), Toward a new theory of organizations (pp. 209-226). London: Routledge.

Weick, K. E. (1996). Sensemaking in organizations. Thousand Oaks, CA: Sage.

Weick, K. E., \& Westley, F. (1996). Organisational learning: Affirming an oxymoron. In S. R. Clegg, C. Hardy, \& W. R. Nord (Eds.), Handbook of organization studies (pp. 440-458). London: Sage.

\section{Acknowledgments}

An earlier version of the paper was presented at the Academy of Human Resource Development International Conference in the Americas held in Houston, Texas in 2014. The authors appreciate the comments of two anonymous reviewers that helped shape the final version of this paper.

\section{Authors}

Roland K. Yeo holds a Ph.D. in Organization Studies from the Leeds Business School, Leeds Metropolitan University and completed his postgraduate studies at the Saild Business School, University of Oxford and the School of Management, HEC Paris. He is currently HRD Researcher and Practitioner in Saudi Aramco, Adjunct Senior Research Fellow at the University 
of South Australia Business School and Adjunct Associate Professor of Management at the King Fahd University of Petroleum \& Minerals in Saudi Arabia. He is currently conducting practicebased research in leadership identity and influence, knowledge boundaries, intra-organizational learning, and relational ethnography.

Jessica Li is Associate Professor and Program Coordinator of Human Resource Development at the University of Illinois at Urbana Champaign. Li served on the board of Academy of Human Resource Development from 2014 to 2018 and is currently on the Advisory Board for the Centre for East Asian and Pacific Studies. She has published extensively including more than 50 journal articles and book chapters, and a co-authored book. Li also worked for corporations like Motorola, Raytheon, and Nokia for a decade. Her Ph.D. is from the Pennsylvania State University. $\mathrm{Li}$ is the Editor-in Chief of Human Resource Development International. 
